\title{
Las producciones de Terra Sigillata Altoimperial de Sisapo (La Bienvenida, Ciudad Real) I. Terra Sigillata Italica y Galica
}

\author{
Carmen Fernández Ochoa* \\ M. Mar Zarzalejos Prieto*
}

Se agrupan en las páginas siguientes una serie de materiales recogidos en superficie como fruto de antiguas remociones del yacimiento. La publicación de los conjuntos descontextualizados de La Bienvenida, ha sido ininterrumpida en los últimos años. En esta línea, hemos dado a conocer el mobiliario metálico (AURRECOECHEA et alii 1986), las lucernas (FERnández Ochoa-Seldas 1987), las gemas (Zarzalejos-Garcia 1987), las ánforas (ZARZALEJOS-Seldas 1987) y las terracotas (FERNANDEZ OCHOA-SAN NICOLAS 1990).

En el presente trabajo abordamos el estudio de la Terra Sigillata, siguiendo la ordenación al uso en materiales de este tipo. Procederemos a analizar en primer término, las importaciones itálicas y gálicas, para finalmente sistematizar los hallazgos de producciones hispánicas '.

* (Departamento de Arqueología U.A.M.)

1 Por razones de espacio, presentamos en esta ocasión el estudio alusivo a las importaciones itálicas y gálicas, reservando el análisis de las producciones hispánicas para el siguiente número de esta misma revista. 


\section{TERRA SIGILLATA ITALICA}

\subsection{Formas lisas}

1. Fragmento de borde de plato de forma Pucci VI, var. 6 (Haltern III/4 a, Goudineau $19 \mathrm{c}$ ), (fig. 1, núm. 1). Barniz tierra siena (R-39) y pasta tierra verde tostada $(\mathrm{M}-49)^{2}$. Presenta borde simple de convexidad acentuada, desprovisto de labio. Cuenta con ranuras internas en las zonas correspondientes al extremo superior del borde y el fondo del plato. Esta forma, producida por la totalidad de los talleres itálicos conocidos, se halla bien documentada en contextos de época augustea. Permanece vigente durante un prolongado marco temporal, tal y como confirma la presencia de marcas in planta pedis sobre alguno de sus ejemplares (Pucci 1985, 382). No se trata de una forma demasiado frecuente, tal y como puede deducirse del número de hallazgos registrados hasta el momento en la Península Ibérica (ETTLINGER 1983, lám. 6, núm. 93 y 94; Delgado et alii 1975, lám. IV, núm. 66 y 67; Pérez González 1989, fig. 7, núm 36, 37 y 38 ).

2. Fragmento de borde de plato de forma Pucci VI, var. 9 (Haltern III/4, Goudineau 30 b), (fig. 1, núm. 2). Barniz tierra siena (R-39) y pasta tierra verde tostada (M-49). Presenta borde simple, desprovisto de labio, con doble ranura al interior. La pared manifiesta convexidad acentuada.

3. Fragmento de borde de plato de forma Pucci VIII, var. 3 (Haltern I/1, Goudineau 17), (fig. 1, núm. 3). Barniz rojo inglés (R-20) y pasta de pardo muy pálido (M-67). Presenta borde vuelto de trayectoria oblicua, limitado en la pared interna por una ranura.

4. Fragmento de borde de plato de posible forma Pucci IX, var. 8 (Oberaden 4), (fig. 1, núm. 4). Barniz tierra siena (S-39) y pasta pardo muy pálido (M-70). Presenta borde algo exvasado, provisto de dos órdenes de molduras. En el interior, pared registra un notable incremento del grosor a medida que se aproxima al fondo interno, al tiempo que se produce cierta complicación del perfil, provisto de ranuras en la zona próxima al labio, y con una moldura en cuarto de círculo en la zona correspondiente al punto de unión entre la pared y el fondo interno. Esta

${ }^{2}$ Los colores de pasta y barniz han sido establecidos mediante el Code des Couleurs des Sols de A. Cailleux. Ed. Boubée. Las observaciones se han efectuado con luz natural en las horas centrales del dia. 
Las producciones de Terra Sigillata Altoimperial de Sisapo ...
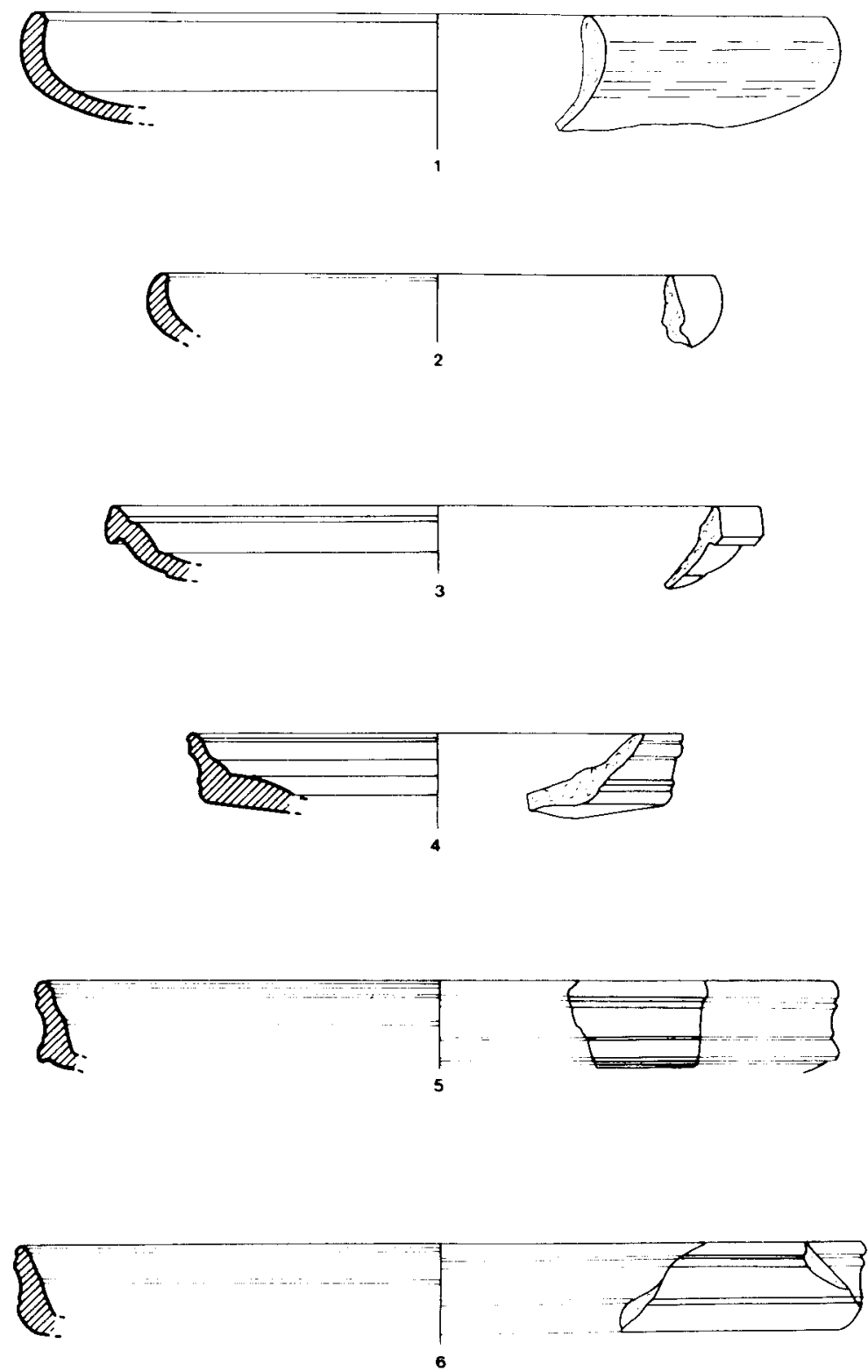

Fig. 1

0

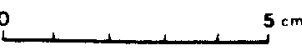


forma presenta una cronología inicial situable entre los años 12-10 a. C. y el 0 , manteniendo su uso vigente al menos, hasta época tiberiana (Puc. Cl 1985, 383).

5. Fragmento de borde de plato de forma Pucci $X$, var. 5, (fig. 1, núm. 5). Barniz tierra siena natural (R-47) y pasta tierre verde tostada (M-35). Presenta borde vertical articulado en tres movimientos, perfectamente marcados por molduras. La pared interna, de configuración bipartita, está provista de abundante molduración en la zona correspondiente al labio, al tiempo que ofrece un perfil general de tendencia oblicua.

6. Fragmento de borde de plato de forma Pucci X, var. 6 (Haltern IV/5, Goudineau 36 a), (fig. 1, num. 6). Barniz tierra siena (R-39) y pasta tierra verde tostada (M-35). Presenta labio de sección redondeada, bien individualizado mediante una moldura. El borde se encuentra articulado en su perfil externo en dos movimientos (cóncavo-convexo), cuyos puntos de inflexión se hallan reforzados por sendas molduras. La pared interna ostenta perfil oblicuo, interrumpido por una ranura en la zona del labio y otra en el sector medio.

7. Fragmento de borde de plato de forma Pucci X, var.31, (fig. 2, núm. 1). Barniz tierra siena (R-39) y pasta tierra verde tostada ( $\mathrm{N}-25)$. Presenta borde sencillo, de trayectoria vertical, articulado en dos movimientos, marcados por sendas molduras. Conserva decoración aplicada, en la que puede reconocerse una figura de deltín pasante a la izquierda. Hemos documentado un motivo análogo en Bolsena (GoudineAu 1968, 211, núm. 96). En territorio peninsular pueden rastrearse representaciones muy similares en Valeria (SÁNCHEZ-LAFUENTE 1985, 36, fig. 6, núm. 22), Conímbriga (DELGADO et alii 1975, lám. IV, núm. 64), Herrera de Pisuerga (Pérez González 1989, fig. 7, núm. 40) y Segóbriga (SÁnChezLAFUENTE 1990, fig. 12, núm. 116).

8. Fragmento de borde de plato de forma Pucci X, var.4 (Haltern II/ 2, Goudineau 25), (fig. 2, núm. 2). Barniz tierra siena (R-39) y pasta pardo muy pálido (M-55). Presenta borde vertical articulado en tres movimientos, con decoración burilada en las zonas convexas. La pared interna manifiesta ligera tendencia oblicua y se halla provista de finas ranuras. Esta tipología presenta según Goudineau, numerosas variantes en el borde (Goudineau 1968, 20, fig. 1, núm. 2). Parece que inicialmente, la forma debió comenzar a producirse en torno al año 10 a.C., aunque algunas de sus variedades pudieron prolongarse hasta momentos muy avanzados (siglo II d. C.) (Puccı 1985, 385).

9. Fragmento de borde de copa de forma Pucci XXIII (Haltern III/ 10-11, Goudineau 29 b, Drag. 27 A), (fig. 2, núm. 3). Barniz tierra siena 
Las producciones de Terra Sigillata Altoimperial de Sisapo ...
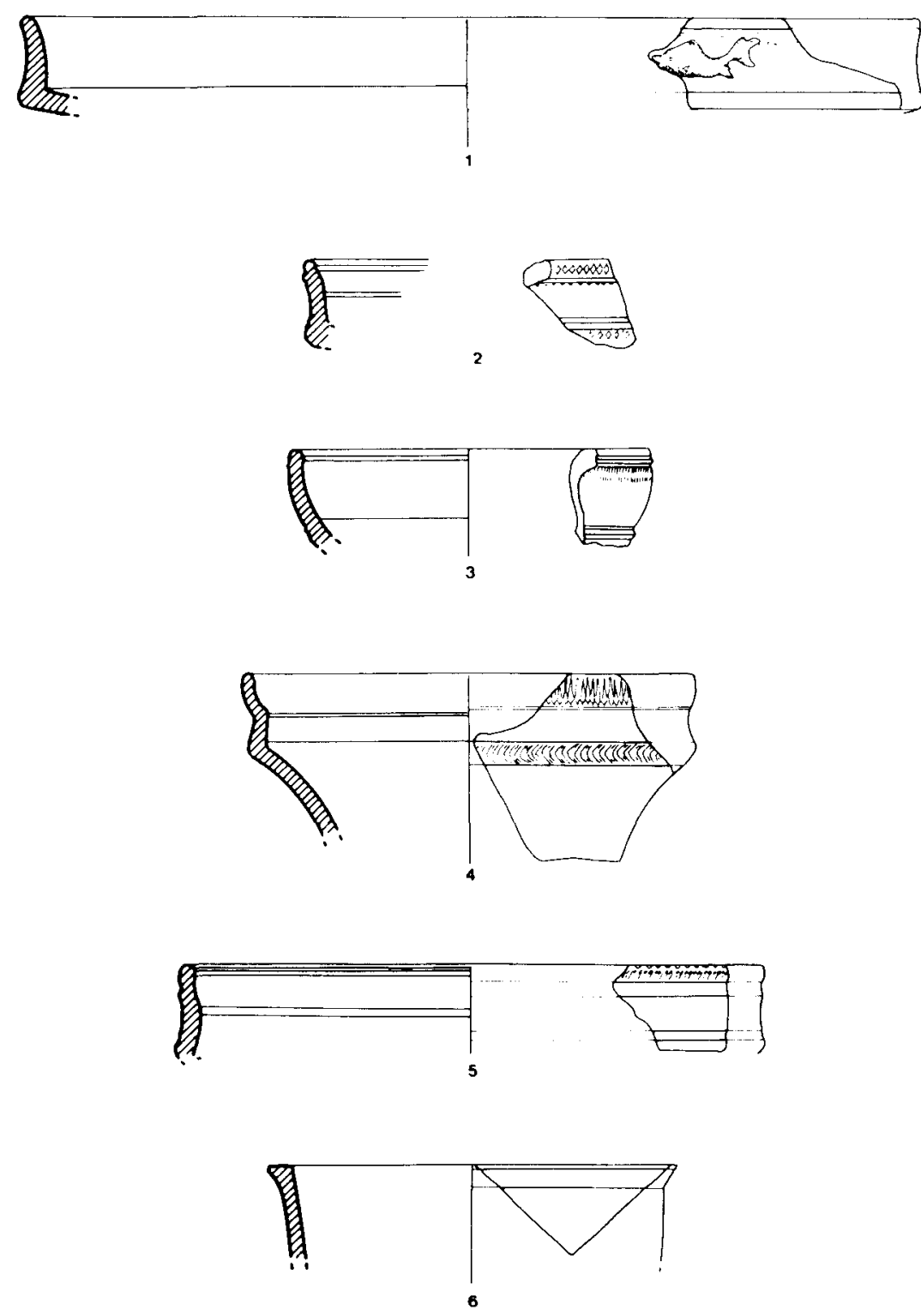

Fig. 2

o

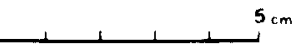


(R-39) y pasta tierra verde tostada (M-47). Conserva un pequeño labio de sección redondeada, claramente aislado del borde mediante una moldura exterior y una ranura interna. El primer cuarto de círculo que caracteriza la forma, registra convexidad poco acentuada y se halla provisto de decoración burilada en la zona superior. El cuarto de círculo inferior no conservado, se hallaba separado del primero mediante dos estrechas molduras.

10. Fragmento de borde de copa de forma Pucci XXV (Haltern II/8, Goudineau 27, Oberaden 8-A, Ritt. 5), (fig. 2, núm. 4). Barniz tierra siena (R-39) y pasta tierra verde tostada (M-35). Presenta borde vertical de configuración tripartita, con puntos de inflexión marcados al interior por ranuras. Las zonas convexas se encuentran provistas de decoración burilada. Conserva parte de la pared, de perfil oblicuo algo incurvado hacia el interior.

11. Fragmento de borde de copa de forma Pucci XXV (Haltern II/ 8), Goudineau 27, Oberaden 8-A, Ritt. 5), (fig. 2, núm. 5). Barniz tierra siena $(R-39)$ y pasta tierra verde tostada (M-35). Presenta borde de trayectoria vertical y sección redondeada. La pared externa cuenta con dos molduras ornamentales, delimitando la superior una banda con decoración burilada. El perfil interno ofrece compartimentación bipartita (cóncavo-convexa), con dos puntos de inflexión marcados por sendas molduras. Esta forma comienza a ser producida por los talleres itálicos en el segundo decenio del siglo । a. C., prolongando su uso hasta época tiberiana e incluso julio-claudia (Puccl, 1985, 392).

12. Fragmento de borde y pared de copa de forma Pucci XXXIX, var. 1, (fig. 2, núm. 6). Barniz tierra siena (R-39) y pasta tierra siena tostada ( $\mathrm{N}-47$ ). Presenta borde exvasado de sección triangular, y pared de tendencia cilíndrica. Este tipo de copa no figura en las tipologías recientes, salvo en la de Pucci, aunque sí se encuentra recogida por Dragendortf (Drag. 4). Su cronología inicial puede situarse en torno al 15 d. C. (Bemont 1976, 220 ss.). Esta variedad se halla documentada en Magdalensberg, en un contexto datable entre el 20-25 y el $45 \mathrm{~d}$. C (Puccl 1985, 397).

13. Fragmento de base de copa de posible forma Pucci XXIII (Haltern III/11, Goudineau 32), (fig. 3, núm. 1). Barniz tierra siena (R-39) y pasta rosa $(\mathrm{M}-20)$. Presenta pie anular elevado, de sección triangular, unido al fondo externo mediante un solo movimiento. Conserva el arranque de la pared, provista de cierta tendencia hemiesférica y decorada con una ranura. 
Las producciones de Terra Sigillata Altoimperial de Sisapo ...
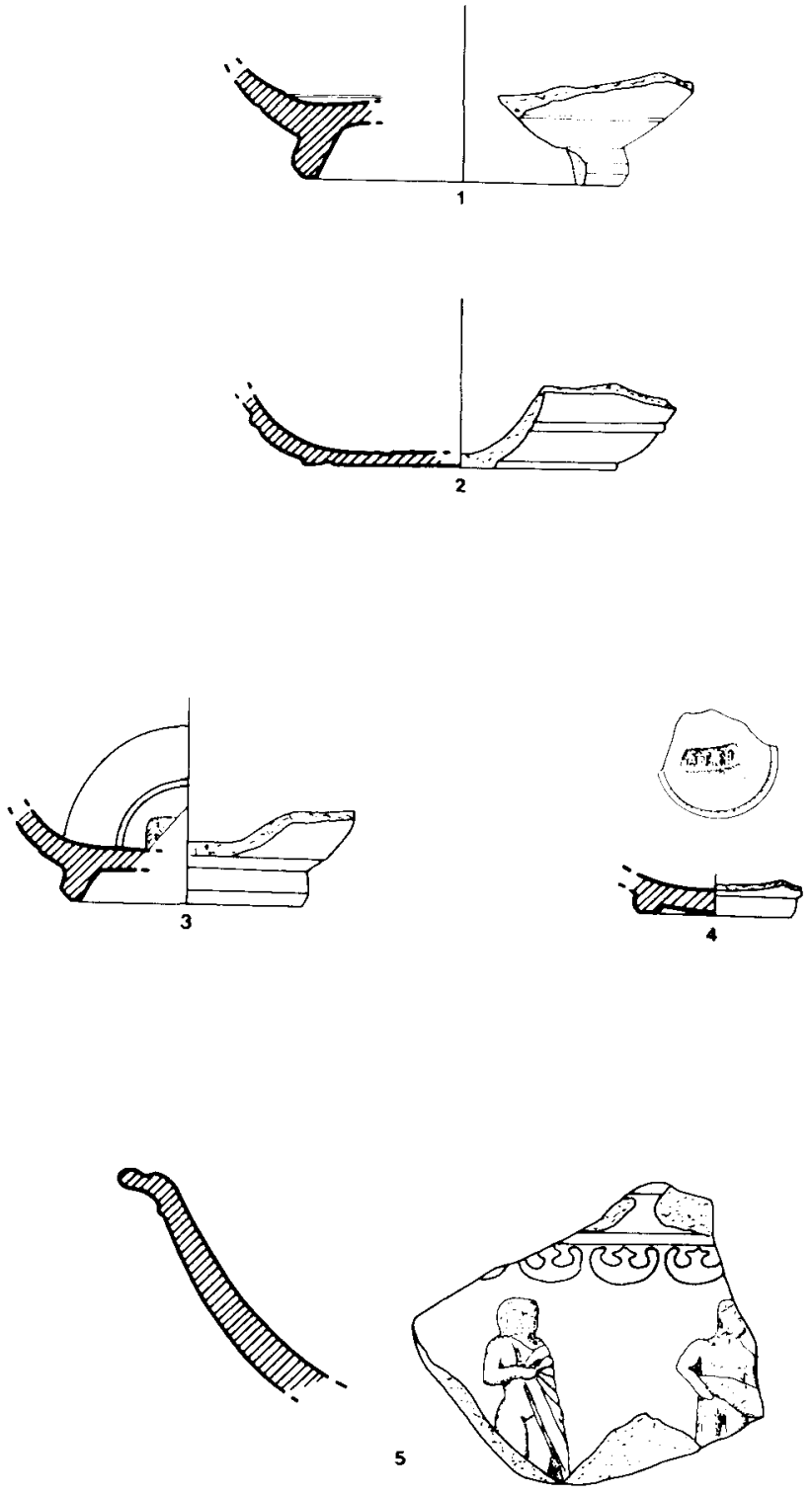

Fig. 3

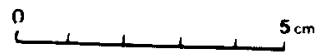


14. Fragmento de base de posible forma Pucci XLI, var. 3 (Haltern IV/6, Goudineau 22 a) (fig. 3, núm. 2). Barniz tierra siena (R-37) y pasta tierra verde tostada ( $\mathrm{N}-25)$. Presenta pie anular extremadamente bajo, situado en la línea del fondo externo. Según Goudineau, esta forma ofrece una cronologia inicial situable en el tercer decenio a. C., aunque resulta algo difícil establecer una datación propia para cada una de las variantes (GOUDINEAU 1968, 295).

15. Fragmento de base de copa de posible forma Pucci XXII, var. 1 (Haltern III/10), (fig. 3, núm. 3). Barniz tierra siena (R-39) y pasta rosa (L-47). Presenta pie anular, de sección triangular y arranque de pared de tendencia troncocónica. En el fondo interno, conserva restos de una marca de oficina, inscrita en una cartela probablemente rectangular. En ella únicamente resulta visible parte de una palma, del tipo de las que aparecen con cierta frecuencia en la T.S.I.

Esta forma, en su variedad más antigua, ha sido datada por Goudineau entre el 10 y el 9 a. C. (GOUdINEAU 1968, 299-300). Las variantes más tardias pueden situarse entre el 5 a. C. y el $3 \mathrm{~d}$. C. (SCHNURBEIN $1982,58)$. Por otra parte, no se trata de un tipo formal demasiado difundido, al tiempo que parece estar relacionado en mayor grado, con los talleres itálicos provinciales que con las oficinas centrales emplazadas en Arezzo (Pucci 1985, 390).

16. Fragmento de base de copa de posible forma Pucci XXV (Haltern II/9, Goudineau 37, Ritt. 5 B), (fig. 3, núm. 4). Barniz tierra siena (R39) y pasta tierra siena natural (N-55). Presenta pie anular bajo, de sección rectangular y fondo interno con marca de oficina inscrita en cartela rectangular de extremos redondeados. Puede leerse sin dificultad ATEI. La firma recoge el nomen de un alfarero establecido inicialmente en Arezzo, que dispersó de modo importante sus productos, merced al establecimiento de sucursales en territorio itálico y francés (STENICO 1968, 61; TAPONECO 1974, 3 ss.). Los productos de Ateius han sido documentados en Conímbriga en contextos datables entre fines del siglo I a. C. y las dos primeras décadas del I d. C. (DELGADo et alii 1975, 40). Nuestro ejemplar podría adscribirse a este mismo parámetro temporal, correspondiente a época tardoaugustea y tiberiana.

\subsection{Formas decoradas}

17. Fragmento de borde y pared de copa, (fig. 3, núm. 5). Barniz tierra siena (S-39) y pasta rosa (L-47). Presenta borde exvasado, con 
labio de trayectoria horizontal y pared de tendencia hemiesférica. De su decoración original, resulta visible una sucesión seriada de peltas, de ejecución similar a las que figuran sobre una pieza procedente de un taller puteolano (COMFORT 1963-64, lám. XV. 4, núm. 22378 y lám. XVI, núm. 22374) y en su ejemplar atribuido a M. Perennius (Brown 1968, 19, lám. XII, núm. 51). Bajo las peltas, conserva restos de una posible escena figurativa, en la que, de izquierda a derecha, aparece un personaje, quizá femenino, desnudo, con un manto sobre el hombro izquierdo, que sujeta con la mano derecha. La segunda figura, de aspecto masculino, aparece representada también desnuda, portando un objeto de imposible identificación, dado el precario estado de conservación de la pieza. No conocemos paralelos para este tipo de representación.

\section{TERRA SIGILLATA GALICA}

\subsection{Formas lisas}

1. Fragmento de borde y pared de forma Drag. 24/25, (fig. 4, núm. 1). Barniz tierra siena (R-39) y pasta tierra siena tostada (M-37). Conserva labio de sección redondeada, individualizado por una ranura interna. Presenta borde vertical con decoración burilada a modo de trama romboidal, enmarcada por líneas de puntos y baquetón de sección redondeada. La pared interna ha sido resuelta en un solo movimiento hacia la base. Los rasgos morfológicos presentes en este ejemplar, permiten adscribirle a época claudio-neroniana (OSWALD-PRYCE, 1966, 171).

2. Fragmento de borde y pared de forma Drag. 24/25, (fig. 4, núm. 2). Barniz rojo inglés (R-20) y pasta rosa (L-25). Presenta borde de trayectoria algo incurvada hacia el interior, carente de labio y provisto de moldura interna. Conserva decoración burilada, constituida por líneas verticales escasamente marcadas y baquetón moldurado, de sección algo apuntada.

3. Fragmento de borde y pared de forma Drag. 24/25, (fig. 4, núm. $3)$. Barniz rojo inglés (R-20) y pasta rojo muy pálido (M-25). Presenta borde de trayectoria vertical, con estrecho labio marcado interior y exteriormente por sendas ranuras. Conserva decoración burilada, con líneas verticales muy desdibujadas, y estrecho baquetón de sección ligeramente apuntada. 

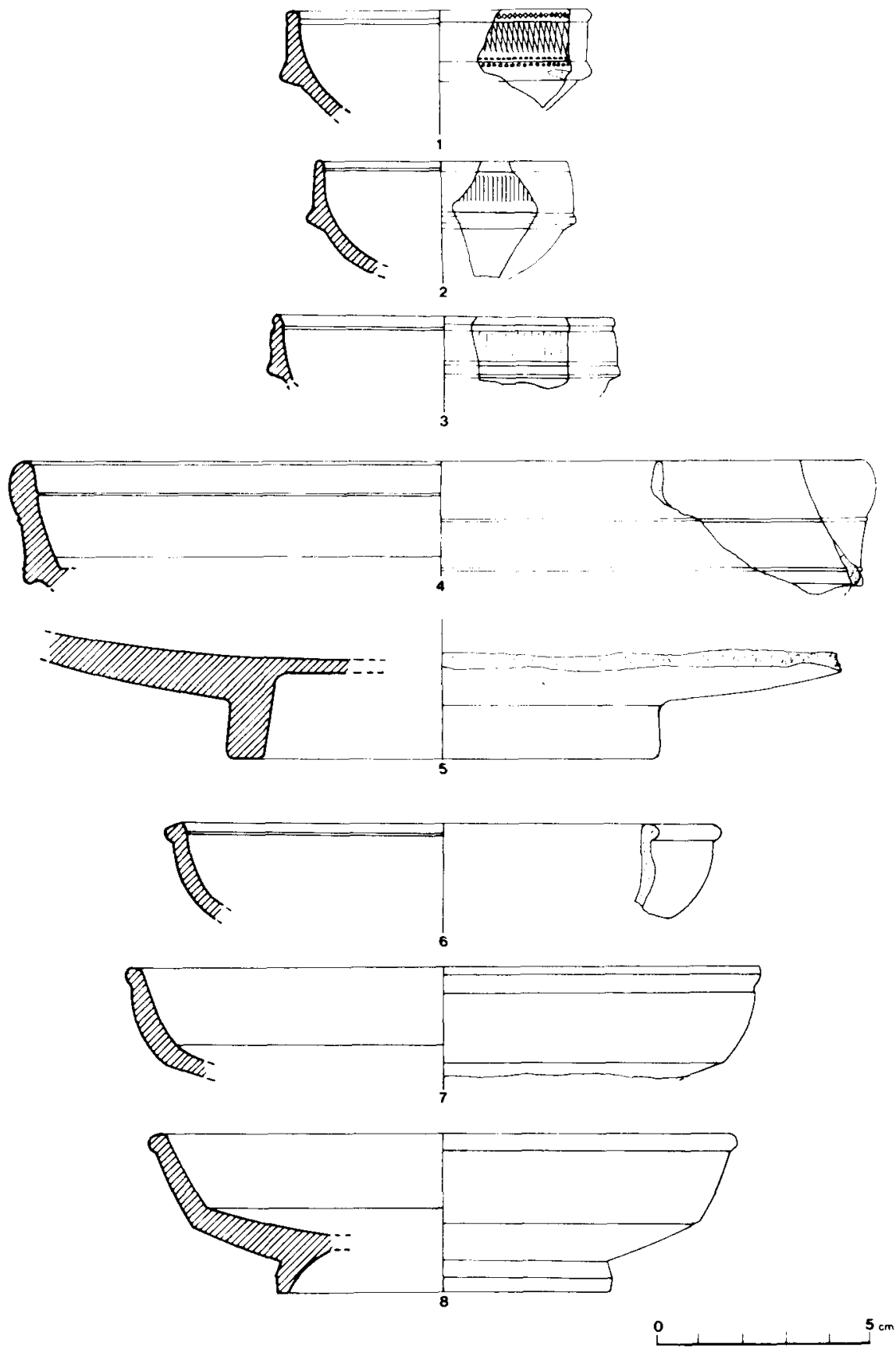

Fig. 4 
4. Fragmento de borde de forma Drag. 15/17, (fig. 4, núm. 4). Barniz rojo inglés (R-19) y pasta tierra siena tostada ( $P-25)$. Presenta borde carente de labio, con ranura interna y pared de compartimentación tripartita al exterior y bipartita en el interior. En el punto de articulación entre la pared y el fondo interno, conserva el arranque de la moldura en cuarto de círculo que caracteriza esta forma. Ejemplares análogos han sido datados en época claudia (OswALD-PRYCE 1966, lám. XLII, núm. 15).

5. Fragmento de base de probable forma Drag. 15/17, (fig. 4, núm. $5)$. Barniz rojo inglés $(\mathrm{R}-20)$ y pasta tierra verde tostada $(\mathrm{N}-25)$. Presenta pie anular elevado, de sección rectangular, unido al fondo externo mediante un único movimiento. El fondo externo mantiene trayectoria ligeramente ascendente.

6. Fragmento de borde de forma Drag. 18, (fig. 4, núm. 6). Barniz rojo inglés (R-20) y pasta tierra verde tostada (N-25). Presenta labio muy marcado al exterior, provisto de una ranura interna y pared de convexidad acentuada. Resulta similar al perfil de una pieza procedente de Mainz, datada en época claudia (Oswald-Pryce 1966, lám. XLV, núm. 9).

7. Fragmento de borde de forma Drag. 18, (fig. 4, núm. 7). Barniz rojo inglés $(\mathrm{P}-20)$ y pasta tierra verde tostada $(\mathrm{N}-25)$. Presenta labio pronunciado, con acanaladura externa. La unión entre el borde y el fondo, se verifica mediante una arista muy marcada con resalte interno. Época claudia.

8. Fragmento con perfil completo de forma Drag. 18, (fig. 4, núm. 8). Barniz rojo inglés (R-20) y pasta tierra siena tostada ( $P-25)$. Conserva un pequeño labio marcado al exterior, de sección redondeada. El borde registra perfil recto de trayectoria oblicua y se encuentra articulado con el fondo, mediante una marcada arista. El pie elevado, de sección triangular, queda unido al fondo externo en un sólo movimiento. El fondo interno manifiesta marcada tendencia descendente. Ciertos rasgos morfológicos documentados en este ejemplar, parecen abogar por su adscripción al grupo de Transición 18/31, fechable en época de DomicianoTrajano.

9. Dos fragmentos de borde de posible forma Drag. $17 \mathrm{~B}$, (fig. 5, núm. 1). Barniz rojo inglés (R-20) y pasta rosa (L-25). Presenta un estrecho labio con doble ranura interna. El borde se halla articulado en un movimiento tripartito al exterior, mientras que en el perfil interno, se resuelve en un único movimiento convexo. 

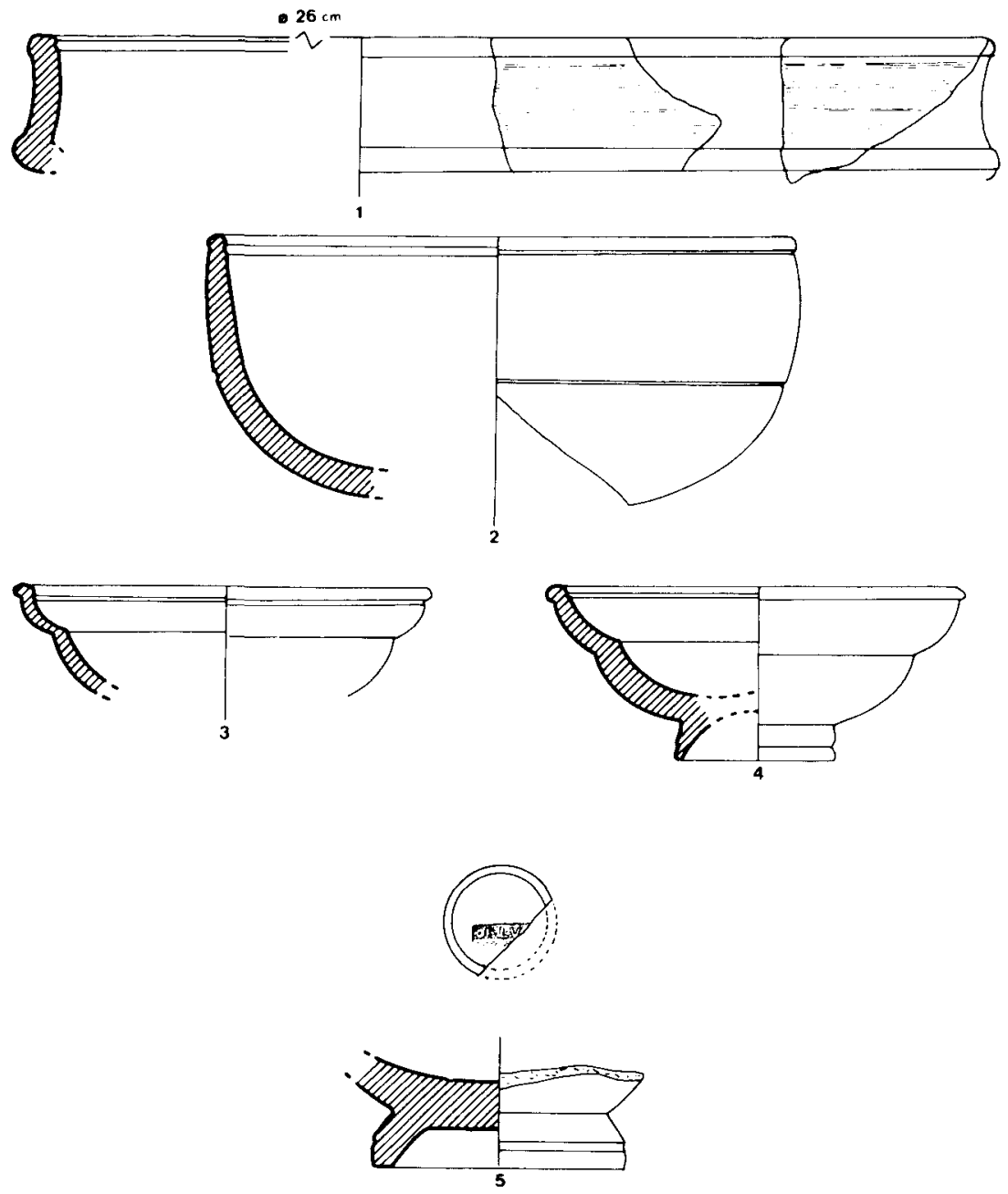

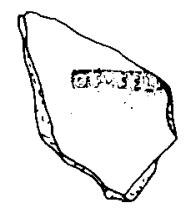

- खायक्य:
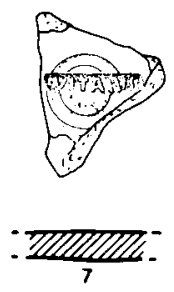

Fig. 5

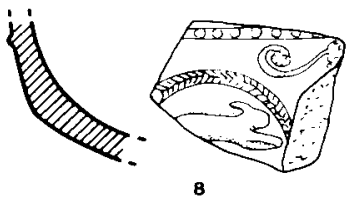

o $5 \mathrm{ein}$ 
10. Fragmento de borde y pared de forma Ritt. 8, (fig. 5, núm. 2). Barniz rojo inglés $(\mathrm{P}-20)$ y pasta tierra verde tostada $(\mathrm{N}-25)$. Conserva un estrecho labio, marcado interior y exteriormente por sendas acanaladuras. La pared, de marcada tendencia hemiesférica, se encuentra provista en su zona media, de una ranura ornamental. Los rasgos morfológicos documentados en este pieza, permiten inscribirla entre los productos tempranos de los talleres sudgálicos, con marcada semejanza respecto a ejemplares de época claudia (OswaLd-PRYCE 1966, 184-185, lám. XLVIII, fig. 7).

11. Fragmento de borde y pared de forma Drag. 27, (fig. 5, núm. 3). Barniz rojo inglés $(\mathrm{R}-20)$ y pasta tierra verde tostada $(\mathrm{N}-25)$. Ostenta un labio pronunciado, marcado interior y exteriormente por una ranura. Este ejemplar presenta un perfil en conjunto, de tendencia fuertemente exvasada, con el primer cuerto de círculo de dimensiones sensiblemente menores a las del inferior.

12. Fragmento con perfil completo de forma Drag. 27, (fig. 5, núm. 4). Barniz rojo inglés $(P-19)$ y pasta tierra siena natural clara (N-37). Presenta labio individualizado por una ranura interna y perfil general, de tendencia bastante exvasada. El pie anular elevado y de sección triangular, está provisto de molduración exterior. El grosor de la pared se incrementa notablemente a medida que se aproxima a la base. El ejemplar puede ser situado en época preflavia (OswALD-PRYCE 1966, 187, lám. XLIX, núm. 2-10 y 13).

13. Fragmento de base de posible forma Drag. 27, (fig. 5, núm. 5). Barniz rojo inglés (R-19) y pasta tierra siena tostada ( $P-25)$. Presenta pie anular elevado y robusto, de sección triangular con molduración externa. El fondo interno conserva estos de una marca de oficina, inscrita en cartela rectangular de extremos oblongos. Puede leerse OF.LU. En nuestra opinión, debe tratarse de un sello atribuible a Lucceius, ceramista de La Graufesenque que desarrolló su actividad en época de Claudio-Vespasiano (OsWALD 1964, 168-169 y 397). Esta marca se encuentra documentada en numerosos yacimientos peninsulares: Ampurias y Tarragona (Oswald 1964, 168-169), Conímbriga, Itálica, Lucentum, Elche y Belo (BALIL 1972, 102) e llurco (ATENCIA et alii 1981, 128).

14. Fragmento de fondo de forma indeterminada (fig. 5, núm. 6). Barniz rojo inglés $(\mathrm{R}-20)$ y pasta tierra verde tostada $(\mathrm{N}-25)$. Conserva una marca de oficina incompleta, inscrita en cartela rectangular de extremos redondeados. Puede leerse OF. FELI, atribuíble a FÉLIX. Ceramistas con este nombre han sido identificados tanto en La Graufesenque como en Montans (OswaLD 1964, 120-121 y 304), e incluso en puntos 
de producción de menor entidad como Valery (MARTiN 1976, 7-10), Crambade y Rozier (MARTIN 1986, 73-75; THUAULT-VERnHET 1986, 112). Por lo que se refiere a la inserción de la actividad de este ceramista en un contexto cronológico, Oswald defiende su adscripción a época claudiovespasiana (OsWALD 1964, 120-121). En Valery sus sellos aparecieron en un vertedero datable entre el 40-70 d.C. y en Rozier, podría situarse entre el 50-80 d.C. Existe constancia de la dispersión de productos de este alfarero en territorio peninsular: Ampurias Tarragona, Conimbriga, Alcañiz y Lorca (BELTRÁN 1978, 101), Numancia, Zaragoza y Monteagudo (Romero, 1985, 45), Padilla de Duero (MAÑANes 1983, 189, fig. 57, núm. 5), Belo (BONNEVILle et alii 1982, 55, fig. 34), Herrera de Pisuerga (PÉrez GONZALEZ 1989, 304-305, fig. 39, núm. 91) y Segóbriga, entre otros (SANCHEZ-LAFUENTE 1990, 143).

15. Fragmento de fondo de forma indeterminada, (fig. 5, núm. 7). Barniz rojo inglés $(R-20)$ y pasta tierra siena tostada (M-39). Conserva una marca de oficina completa, inscrita en cartela rectangular de extremos redondeados. El sello, correspondiente a VITALIS, supera en dimensiones el enmarque de la ranura circular que figura en el fondo. Este alfarero desarrolló su actividad en La Graufesenque durante el período Claudio-Domiciano (Oswald 1964, 341). La presencia de productos de este ceramista galo, se encuentra atestiguada en otros puntos peninsulares: Ampurias, Tarragona, Elche, Sagunto, Gerena (Sevilla) y Azimbal (Portugal) (Beltrán 1978, 103), Ilurco (Pinos Puente, Granada) (AtEnCia et alii 1981, 129) y Segóbriga (SÁNCHEZ-LAFUENTE 1990, 164).

\section{II.2. Formas decoradas}

16. Fragmento de pared de forma Drag. 29, (fig. 5, núm. 8). Barniz tierra de sombra tostada (P-29) y pasta tierra verde tostada $(\mathrm{N}-25)$. Conserva parte de una de las zonas decorativas del vaso, limitada en su extremo superior por un estrecho baquetón con línea de perlas. Puede reconocerse un motivo circular sogueado, con punzón lagomorfo inscrito, pasante a la derecha y en actitud de carrera. Así mismo, resulta visible parte de una guirnalda rematada en roseta de seis pétalos. El punzón animal se encuentra bien representado en La Graufesenque (HERMET 1934, lám. 32, núm. 7 y 8) y de modo general, en el conjunto de la T.S.G. (DECHELETTE 1904, 141-142). 


\section{ESTUDIO}

\section{Terra sigillata Italica}

El material de origen itálico proporcionado por el yacimiento íberoromano de la Bienvenida, asciende núméricamente a un total de 17 ejemplares.

El conjunto, la representación de los productos de filiación itálica o provincial, resulta minoritaria en relación a las cifras totales de terra sigillata producidas por el yacimiento, evaluables hasta el presente en 3.058 ejemplares ${ }^{3}$. En el marco de referencia constituido por las 17 piezas que se incorporan a este análisis, la proporción entre formas lisas y decoradas se decanta claramente a favor de las primeras. En efecto, tan sólo contamos con un ejemplar decorado, frente a 17 lisos, en una relación de inferioridad numérica constatada en otros yacimientos peninsulares como Numancia (Romero 1985, 30), Conímbriga (Delgado et alii 1975, 7), Valeria (SÁNCHEZ-LAfUente 1985, 31), Herrera de Pisuerga (PEREZ GONZÁLEZ 1989, 171) o Raïmat (Lérida), donde los 71 fragmentos aparecidos corresponden en su totalidad a formas lisas (PÉREZ ALMOGUera et alii 1988, 47).

Siguiendo el orden adoptado en la presentación del catálogo, abordaremos en primer lugar las consideraciones alusivas a los ejemplares lisos. No vamos a detenernos en reiterar asuntos relacionados con la trayectoria de las investigaciones que este tipo cerámico ha experimentado desde los estudios de Dragendorff hasta nuestros días, puesto que el tema ha sido sintetizado muy recientemente (Pucci 1985, 371-375); Pérez González 1989, 178-180). Sí resulta conveniente indicar, que la clasificación de las piezas ha sido realizada de acuerdo con la tipología morfológica elaborada por G. Pucci, añadiendo en su caso, las equivalencias con los cuadros tipológicos de Loeschke y Goudineau.

En principio cabe señalar que las formas abiertas se encuentra en situación de paridad respecto a las cerradas. Los fragmentos correspondientes a platos, ascienden a ocho ejemplares, todos ellos pertenecientes al borde de los recipientes.

3 Se ha contabilizado la totalidad de los materiales generados hasta el presente por el yacimiento. Un conjunto constituido por 48 piezas corresponde a los cortes estratigráficos E-2 y F-2, analizados en la memoria Sisapo I (FERNANDEZ OCHOA et alii 1990). 
A la forma $\mathrm{VI}$, consideramos adscritos dos fragmentos (fig. 1, núm. 1 y 2) con rasgos propios de las variantes 6 y 9 respectivamente. Este grupo comprende una serie de platos caracterizados prioritariamente por la convexidad de la pared, equivalentes a los tipos Haltern III,4 y IV,5 B, Goudineau 19, 30 y 36b y Oberaden 2 y 3 (Puccl 1985, 381). Desde el punto de vista cronológico, se trata de una forma de perduración prolongada, perfectamente documentada en época augustea, aunque con manifestaciones más tardías tal y como acredita la presencia de sellos in planta pedis sobre algunos ejemplares (PuCCI 1985, 382; ETTLINGER 1983, 58-59).

En la forma VIII hemos catalogado un fragmento (fig. 1, núm. 3). Este tipo agrupa una serie de platos provistos de borde con articulación variada y pie anular, correspondientes al servicio Haltern la, I b y c de Fellmann, Oberaden 1 y formas 15, 17 y 23 de Goudineau (Puccl 1985, 382). La pieza corresponde a la variante 3 del tipo, con características propias del servicio lc de Fellmann, como la moldura cóncava registrada por la pared interna a la altura del labio (Goudineau 1968, 49). El punto de partida de esta forma, puede situarse en torno al 15 a. C., manteniendo su convivencia con otros tipos de plato, especialmente el de forma $X$ (Puccl 1985, 382). La variante de borde correspondiente al servicio I c de Fellmann, puede situarse entre el 12 y el 1 a. C., con alguna perduración que en ciertos yacimientos como Herrera de Pisuerga, no debió sobrepasar el año 10 d. C. (PÉrez González 1989, 182).

Otra forma abierta documentada en este estudio, corresponde al tipo IX individualizado por Pucci y equivalente al servicio Haltern I//3 b, Goudineau 28 y Ritt. 4 c. Se trata de platos con borde de configuración tripartita al exterior y bipartita en la pared interna, provistos de una moldura convexa en el punto de articulación entre la pared y el fondo interno. Esta forma se encuentra representada en sólo una ocasión, perteneciente a la variante 8 (fig. 1, núm. 4). La cronología inicial del tipo puede ser fijada en torno al 12-10 a. C. y el año 0. Debió continuar en uso durante época tiberiana, al tiempo que existe noticia de su producción por talleres tardoitálicos en el período flavio (Pucci 1985, 383). En Bolsena, la forma está presente en contextos datables entre los años 1 y 3 d. C. (GoudiNEAU 1968, 299).

El tipo abierto más representado en el yacimiento sisaponense corresponde a la forma $X$ de Pucci. Se trata de un grupo heterogéneo de platos, con numerosas variantes reconocidas en cuanto al borde y la configuración general de la pared. La ausencia de rasgos definidores de un tipo único, explica la agrupación bajo esta forma, de un importante número de variantes morfológicas equivalentes a los servicios II y IV de 
Haltern, 2 y 5 de Loeschke y 20 a, 25 b, 26, 36 a y 39 de Goudineau (PuCCl 1985, 383). Dentro de la heterogeneidad que caracteriza esta forma, resulta posible admitir cierto grado evolutivo, entre las variedades de borde más complejo y aquellas otras más simples. Sin embargo, en nuestro estado actual de conocimientos, no parece verosímil asignar a esta evolución formal, connotaciones cronológicas precisas, aplicables a cada uno de los centros de producción conocidos (WELLS 1977, 2 ss.).

El número de fragmentos catalogados bajo esta forma asciende a 4 ejemplares. Las variantes 4 y 5 , se encuentran representadas en una sola ocasión (fig. 2, núm. 2 y fig. 1, núm 5). La variante 6 ha sido documentada de igual modo, por un sólo fragmento (fig. 1, núm. 6). Finalmente, contamos con una representación del subtipo 31 (fig. 2, número 1).

La cronología propuesta para esta forma, puede resultar tan amplia como los rasgos formales incluidos en ella. Parece que inicialmente, este tipo de plato comenzó a ser producido en época augustea (10 a. C.), si bien su perduración pudo ser importante, tal y como permite suponer su fabricación por talleres tardoitálicos. Tal género de imprecisiones, únicamente podrá ser resuelto, a medida que se inicie un estudio monográfico de esta forma, en el que debería prestarse especial atención a los análisis físico-químicos, a fin de proceder a la distinción de los centros que la produjeron (PuCCl 1985, 385).

El volumen total de ejemplares correspondientes a formas cerradas - tazas y copas-, se eleva a ocho. La forma XXIII se encuentra representada por dos ejemplares (fig. 2., núm. 3; fig. 3, núm. 1). Bajo ella, Pucci engloba los tipos Haltern 7, 10 y 11 y Goudineau 32 (Puccl 1985, $390)$. Se trata de una copa con pie anular, provista de borde convexo y estrechamente relacionada con la forma XXII. Este tipo de copa documentado en Bolsena y Haltern y ausente de Oberaden y Rödgen, debió comenzar a producirse entre los años 1 y $5 \mathrm{~d}$. C., si bien, la forma canónica no se implanta hasta el 10 d. C. (Puccl 1985, 391). Su perduración temporal parece estar constatada al menos, hasta mediados del siglo । d. C., tal y como parece sugerir su presencia en Pompeya (Puccl 1977, lám. II, núm. 12).

El tipo de copa más abundante en el yacimiento sisaponense, es sin duda la forma XXV de Pucci, equivalente al servicio Haltern II/8 y II/9, Goudineau 20 c, 25,27 y 37 , Ritt. $5^{4}$.

${ }^{4}$ Tal dato aparece corroborado en la estratigrafía mediante una clara superioridad numérica de este tipo de copa (Vid. Fernandez Ochoa et alii 1990). 
Incluye un importante número de variantes, caracterizadas en términos generales, por la presencia de un cuerpo troncocónico, con borde de configuración tripartita al exterior y bipartita en la superficie interna. Existen, no obstante, ciertas variedades con menor complejidad en el borde y provistas de mayor verticalidad en la pared (Pucci 1985, 391).

El número total de fragmentos de superficie adscritos a esta forma, asciende a tres. De ellos, dos corresponden al borde la pared y el restante a la base. Con la variante 4 , equivalente al tipo Haltern $11 / 8$, ha sido posible relacionar uno de nuestros ejemplares (fig. 2, núm. 4). La pieza resulta prácticamente idéntica a una de los perfiles reconocidos en Herrera de Pisuerga (Pérez González 1989, fig. 14, núm. 119). La ausencia en nuestro caso, como en el yacimiento herrerense, de la base de la copa, permite concebir dudas sobre su relación con la forma Haltern II/8, Goudineau 27 o con los tipos Haltern II/9, Goudineau 37. La distinción entre ambas formas puede convertirse en problemática, dadas la similitudes existentes en la configuración del borde y la pared (PÉREZ GONZÁLEZ 1989, 96, núm. 119). Este mismo autor expresa a modo de hipótesis, la posibilidad de que se trate de la misma forma Haltern II/8 en un estadio de evolución lógico experimentable desde su aparición, hasta el inicio de la forma Goudineau 40 (PÉrez GonzÁlez 1989, 96).

Por lo que respecta al marco temporal admitido para este tipo, hemos de anotar un grado importante de perduración, ligado sin duda, al numeroso grupo de variantes establecidas en él. Parece que los perfiles más tempranos hacen su aparición en el segundo decenio del siglo 1 a. C., manteniéndose en uso hasta época tiberiana. Las variedades más tardias pudieron prolongarse hasta época julio-claudia (Puccı 1985, 392). Inicialmente debió ser fabricada en Puteoli, pasando en un segundo momento a formar parte de la producción de la propia Arezzo y las sucursales provinciales (SCHNURBEIN 1982, 39 ss.).

Con la forma XXXIX hemos relacionado un fragmento de borde (fig. 2 , núm. 6). Bajo este tipo resulta unificada una serie de tazas cilindricas, carentes de pie o bien provistas de uno muy bajo. La forma se halla ausente de la tipologías recientes, aunque corresponde al tipo 4 de la primera clasificación de Dragendorff (Puccl 1985, 397). La pieza posee borde exvasado de sección triangular y pared de trayectoria cilíndrica. La cronología aplicada a este tipo de taza podría partir inicialmente del año $15 \mathrm{~d}$. C., teniendo en cuenta además, que fue producida en mayor medida por alfareros no aretinos (BEMONT 1976, 220 ss.).

En términos de duda hemos planteado la atribución de una de nuestras bases a la forma XLI (fig. 3, núm. 2). Presenta pie anular extrema- 
damente bajo y arranque de pared de trayectoria vertical. Esta forma incluye los tipos Haltern 16, Oberaden 12 y Goudineau 22 (Puccl 1985, 397). La cronología propuesta por Goudineau situa su punto de arranque, en el tercer decenio a. C., si bien debe hacerse constar la existencia de variantes más tardias, provistas de decoración a barbotina (GoudINEAU 1968, 295; Porten PaLANGe 1966, 85, lám. XXXIII, núm. 148).

Una vez que hemos procedido al repaso de las formas lisas documentadas por los aportes superficiales del yacimiento, conviene aludir brevemente a la información proporcionada por la única marca de oficina relacionada con los hallazgos descontextualizados que venimos presentando. Se trata de una firma perteneciente a ATEIVS, inscrita en cartela rectangular y con especificación del nomen del alfarero. La actividad de este ceramista en la Península lbérica se encuentra perfectamente testimoniada por el hallazgo de numerosos sellos en puntos tan alejados como Herrera de Pisuerga, Numancia, Conímbriga, Córdoba, Itálica, Pollentia, Segobriga o Mérida.

Por lo que respecta al centro de procedencia de los productos de Ateius, habrá de tenerse en cuenta la diversificación de sucursales establecidas por este próspero ceramista fuera del núcleo original de Arezzo. En efecto, existe constancia de su actividad en Pisa (TAPONECO 1974, 3 ss), en La Muette (Lyon) (PICON et ali 1972-73, 128-135) y quizá también en La Graufesenque (SÁNCHEZ-LAFUENTE 1990, 65); incluso podria mantenerse a modo de hipótesis, la existencia de una posible sucursal establecida en suelo hispano (PÉrez GonzAlez 1989, 144). Los productos de Ateius han sido documentados en Conímbriga en niveles datables entre fines del siglo । a. C y los dos primeros decenios de । d. C., con mayor frecuencia de aparición en contexto tiberiano (DELGADO et alii 1975, 40).

Con respecto a las formas decoradas, es de destacar la presencia de un ejemplar inscrito en esta categoría (fig. 3, núm. 5). El fragmento reivindica conexiones decorativas con una pieza atribuida al taller de $M$. PERENNIUS. Desafortunadamente los motivos humanos presentes en esta pieza, se encuentran en un estado de conservación tan deteriorado, que impiden asegurar cualquier otro extremo de la atribución propuesta.

\section{Terra sigillata Galica}

Sobre un total de 463 fragmentos de T.S.G. proporcionados por el yacimiento sisaponense, 16 piezas son fruto de hallazgos superficiales. 
Ya que hemos iniciado estas consideraciones aludiendo a la representación númerica de este conjunto material, parece conveniente proseguir, antes de adentrarnos en la síntesis formal, con ciertas aclaraciones cuantitativas, interesantes de cara a la emisión de resultados parciales. Si se procede a una relación comparativa que ilustre sobre la presencia de los materiales de procedencia itálica y gálica en La Bienvenida, el resultado arrojará valores distintos, según se manejen las cifras totales del yacimiento o las emitidas por el área abordada en este estudio. Así en el primero de los casos, se detecta una clara superioridad númerica a favor de los productos gálicos - 463 ejemplares - frente a los itálicos -169 fragmentos-. La proporción resulta bastante más equilibrada e incluso algo invertida, en el conjunto procedente de los hallazgos de superficie.

Una vez expuesta estas aclaraciones, conviene anotar la existencia de un claro predominio de las formas lisas (15 ejemplares) sobre las decoradas (un fragmento). Diferencias de esta índole, han podido constatarse en buen número de yacimientos hispanos como Conímbriga (DELGADO et alii 1975, 69), Valeria (SANCHEZ-LAFUENTE 1985, 43) Raïmat (Lérida) Pérez Almoguera et alii 1988, 51 ss.) y Herrera de Pisuerga (Pérez GONZÁLEZ 1989, 319), entre otros muchos.

La formas lisas más profundamente representadas en este conjunto, corresponden a los platos Drag. 18 y 15/17 y los bols Drag. 27 y 24/25. El resto de los tipos documentados, adquieren un carácter casi insignificante. Esta distribución morfológica, no hace sino reivindicar nuevamente resultados obtenidos en otros puntos de la geografía peninsular. Así mismo el predominio de cuatro formas habitualmente consideradas como parte de dos servicios de uso, podría aportar cierta información suplementaria. Las investigaciones desarrolladas a tal efecto sobre el cargamento del navío Culip IV, han permitido comprobar la asociación existente entre las formas Drag. 15/17-Drag. 24/25 y Drag. 18-Drag. 27, plato y bol respectivamente (NIETO 1986, 92). Si este tipo de análisis resulta de gran interés, en nuestro caso la muestra proporcionada por el volumen aqui estudiado, se revela insuficiente como para argumentar razonablemente estos extremos.

El número de ejemplares adscritos a la forma Drag. 15/17, se limita a tan sólo dos. En conjunto, las piezas analizadas presentan rasgos morfológicos propios de las producciones de época claudia, tal y como se ha ido apuntando en el comentario individual de los ejemplares. Esta forma se encuentra abundantemente representada entre los repertorios gálicos de buena parte de yacimientos peninsulares con facies altoimperial. Su importante volumen de emisión y registro, puede venir explicado en parte, 
por un largo periodo de vigencia. En efecto, la forma comienza a fabricarse en La Graufesenque hacia el año $30 \mathrm{~d}$. C., arrivando a los primeros años de la centuria siguiente (VERNHET 1975, VI).

A la forma Drag. 18 corresponden tres fragmentos, pertenecientes mayoritariamente a época claudio-neroniana. Este tipo de plato comienza a ser producido por La Graufesenque hacia el año $30 \mathrm{~d}$. C. (VERNHET 1975 , VI). Las piezas más tempranas (fig. 4 , núm. 7 y 8) presentan en el punto de articulación entre la pared y el fondo, aristas poco marcadas y pared interna de concavidad acentuada (OswALD-PRYCE 1966, 181). Contamos además con un ejemplar provisto de rasgos más avanzados (fig. 4, núm. 8), cercanos a los documentados por la forma de transición Drag. 18/31 (OSWALD-PRYCE 1966, 182).

El cuenco de forma Drag. 24/25, se encuentra representado en este estudio también por tres ejemplares. De acuerdo con el diámetro del borde, ha sido posible aplicar ciertos matices cronológicos (PEREZ GONZÁLEZ 1989, 320). En el margen situado entre el 40 y 60 d. C., la emisión de cuencos de grandes dimensiones, comienza a ceder paso a la de piezas de tamaño más reducido. A esta disminución del calibre general, se sumaría la presencia en algunos de nuestros ejemplares, de caracteres morfológicos propios de la forma a partir de época claudia. Entre ellos cabe destacar, la articulación de la pared interna en un único movimiento (fig. 4, núm. 1), o la presencia de un marcado labio con ranura interna, rasgo éste documentado en gran parte de las piezas pertenecientes a otros sectores del yacimiento.

En líneas generales, puede anotarse como punto de partida para la fabricación de esta forma en los talleres sudgálicos, la época de Tiberio, si bien experimenta su mayor apogeo durante el periodo claudio-neroniano (OSWALD-Pryce 1966, 171). La hipótesis de su virtual desaparición a inicios de época flavia (HoffmanN 1986, 59), puede ser matizada por su presencia en Conímbriga en estratos de época trajanea (DELGADO et alii $1975,92)$ y el dato de superioridad numérica en la categoria de cuencos, reflejada por el pecio Culip IV, cuya fecha de naufragio ha sido situada entre los años 65-80 d.C. (Nieto 1986, 100; Nieto et alii 1989, 235).

Otro tipo de cuenco representado en el conjunto superficial del yacimiento sisaponense, corresponde a la forma Drag. 27 (tres ejemplares). Este vaso, derivado de la copa itálica Pucci XXIII (Haltern 11, Goudineau 32), forma parte del repertorio de los alfareros sudgálicos desde el momento en que se inicia esta producción. Los ejemplares más tempranos suelen presentar marcado labio de sección triangular, provisto de ranura interna y base exterior dotada también de ranuras (VANDERHOEVEN 1984 , lám. 19). Estas características situables en época pre-flavia, han podido 
ser identificadas sobre gran parte de los perfiles correspondientes a la serie analizada (fig. 5, núm. 3, 4 y 5). El período de mayor apogeo en la fabricación de esta forma por los talleres del Sur de Francia, ha sido situado en época claudia, si ben su vigencia permenece inalterada durante la fase flavia (OSWALD-PRYCE 1966, 187). A partir del último cuarto del siglo । d.C., se producen ciertas modificaciones formales que afectan al labio y a la pérdida de la molduración externa del pie. Los ejemplares más tardios, situables ya en el siglo II d.C., presentan labio de sección redondeada, desprovisto de la ranura interna que caracterizaba las producciones de época preflavia (VANDERHOEVEN 1984, lám. 19).

Pese a su exigua proporción, especial interés revisten por su temprana cronología, los fragmentos adscritos a las formas Ritt. 8 y Drag. $17 \mathrm{~B}$ (fig. 5 , núm. 2 y 1 respectivamente).

El cuenco Ritt. 8 de fabricación gálica, resulta un tipo no demasiado frecuente en los conjuntos materiales proporcionados por yacimientos peninsulares. La forma clásica, provista de un pie de reducidas dimensiones, permanece vigente hasta el fin del reinado de Claudio (HofMANN $1986,59)$ o hasta el inicio de época flavia, tal y como proponen otros autores (VANDERHOEVEN 1984, lám. 22). Los resultados obtenidos en Conímbriga, contrastan con la relativa escasez de la forma en territorio hispano. El yacimiento luso ha documentado en efecto, una abundante presencia de este tipo de cuenco, dotada del interés adicional que confieren las precisiones estratigráficas que permiten situar algunos de sus ejemplares en época claudia (DELGADO et alii 1975, 91-92).

Hemos de anotar, así mismo, la presencia de un excelente ejemplar adscrito a la forma Drag. $17 \mathrm{~B}$ (fig. 5, núm. 1). Este tipo de plato, derivado del itálico Haltern 2, se halla ausente de la mayor parte de los yacimientos peninsulares con probada documentación de importaciones gálicas (Numancia, Herrera de Pisuerga, Conímbriga, etc.). En Valeria tan sólo ha podido registrarse un ejemplar de estas características (SANCHEZLAFUENTE 1985, fig. 17, núm. 103).

Por lo que respecta a las marcas de alfarero, únicamente contamos con la información proporcionada por los cuatro ejemplares que han podido ser identificados. Dos de ellas se encuentran relacionadas con oficinas establecidas en el gran centro meridional de La Graufesenque. Se trata de los sellos atribuidos a LUCCEIVS y VITALIS (fig. 5, núm. 5 y 7 respectivamente), sobre cuya dispersión hemos realizado el oportuno comentario en el catálogo.

Algo más problemática resulta la adscripción a un centro concreto del caramista FELIX, puesto que sellos con este nombre han podido ser 
documentados tanto en La Graufesenque o Montans (OswaLD 1964, 384) como en otros puntos de entidad menor, tales como Valery (MARTiN 1976, 7-10), Crambade o Rozier (MARTín 1986, 73-75; THUAULT-VERNHET 1986, 112). Esta duda, igualmente planteada por el ejemplar de Herrera de Pisuerga, ha sido resuelta en este caso, asignando la firma de La Graufesenque en virtud de la presencia dominante en el yacimiento de productos claramente relacionados con este centro ruteno (PÉREZ GONZÁLEZ 1989, 322). Bastante más clara resulta la atribución del ejemplar documentado en Numancia, puesto que la marca de oficina se halla registrada sobre un vaso de forma Drag. 29 realizado en marmorata (RoMERO 1985, 45).

El problema de la distinción entre los homónimos FELIX radicados en La Graufesenque y Montans, podria resolverse si efectivamente se constatara la matización cronológica efectuada por Simpson en su estudio sobre materiales decorados de este último centro (SIMPSON 1976, 263 y 265). Este autor situa la producción del alfarero de La Graufesenque a mediados del siglo। d.C., mientras que el establecido en Montans se mantendría activo durante la primera mitad del siglo ॥ d.C. La ausencia en nuestro caso, de materiales sudgálicos de datación tan avanzada, podría ser argumento a favor de la atribución de esta marca a La Graufesenque.

Finalmente, por lo que respecta al material decorado, únicamente podemos reseñar un fragmento de Dra. 29 cuyo elemento decorativo parece reivindicar conexiones con el centro ruteno de La Graufesenque (fig. 5, núm. 8). 
BIBLIOGRAFIA

Aurecoechea et alii 1986: Aurrecoechea, J., Fernández Ochoa, C. y CABAllero, A., «El mobiliario metálico del yacimiento ibero-romano de La Bienvenida en la Provincia de Ciudad Real», Oretum, II. Ciudad Real.

BALIL 1972: Balil ILLANA, A., «Estudios de cerámica romana IIl», Studia Archaeologica, 13. Santiago de Compostela.

Beltran 1978: Beltran Lloris, M., Cerámica romana. Tipología y clasificación. Zaragoza.

BEMONT 1976: BEMONT, C., Recherches méthodologiques sur la céramique sigillée. Les vases estampillés de Glanum. Ecole Française de Rome. Paris.

BONNEVILLe et alii 1982: BonNeVILLE, J. N. et alii, "La seizième campagne de fouilles de la Casa de Velázquez, à Belo en 1981", Melanges de la Casa de Velázquez, XVIII, 2. Páris.

Brown 1968: Brown, A. C., Catalogue of Italian Terra Sigillata in the Ashmolean Museum. Oxford.

COMFORT 1963-64: COMFORT, H., «Puteolan Sigillata at the Louvre», Rei Cretariae Romanae Fautorum, Acta V-VI.

- 1968: «Terra Sigillata», Estratto dalla Enciclopedia dell'Arte Antica Classica e Orientale. Roma.

DECHELETTE 1904: Les vases céramiques ornés de la Gaule romaine. Paris. Delgado et alii 1975: Delgado, M., Mayet, F., Moutinho de Alarçao, A., Fouilles de Conimbriga IV. Les sigillées. París.

ETTLINGER 1962: ETTLINGER, E., "Vorbemerkunge zu einer Diskusion des Ateius-Problems", Rei Cretariae Romanae Fautorum, Acta IV.

- 1983: "The Terra Sigillata of the excavation at Sa Portella, Alcudia, Mallorca", Pollentia, 3, Sa Portella, excavaciones 1957-1963. Palma de Mallorca. 
Fernández Ochoa-Seldas, 1987: Fernández Ochoa, C. y Seldas FerNANDEZ, I., "Lucernas romanas de La Bienvenida (Ciudad Real)", Oretum, III. Ciudad Real.

Fernández OChoa et alii 1990: Fernández Ochoa et alii, Sisapo 1. Excavaciones en el yacimiento iberorromano de La Bienvenida (Almodóvar del Campo, Ciudad Real). Memoria presentada a la Consejeria de Cultura de la Junta de Comunidades de Castilla-La Mancha, para publicación.

Fernández Ochoa-San Nicolás 1990: Fernández Ochoa, C. y San NicoLAS, P., "Terracotas romanas de Sisapo (La Bienvenida, Ciudad Real)", Homenaje al Prof. Blázquez (en prensa).

GaRCiA Y BELLIDO 1970: “Los hallazgos cerámicos del área del templo romano de Córdoba", Anejos del Arch. Esp. Arq., V. Madrid.

GENTY-FICHES 1978: GENTY, P. Y FICHES, J. L., "L' atelier de potiers galloromain d'Aspiran (Hérault). Synthèse des travaux de 1971 à 1978", Figlina, 3. Lyon.

Goudineau 1968: Goudineau, Ch., Fouilles de l'Ecole Prançaise de Rome à Bolsena. IV. La céramique aretine lisse. París.

Hermet 1934: Hermet, F., La Graufesenque (Condatomago). Paris.

Hofmann 1986: Hofmann, B., La céramique sigillée. París.

Mañanes 1983: Mañanes, T., Arqueologia vallisoletana, II. Torozos, Pisuerga $y$ Cerrato. Valladolid.

MARTIN 1976: MARTiN Th., "L'atelier de Valéry (Tarn). Ses raports avec ceux de Montans", Figlina, 1. Lyon.

- 1986: "Montans", La terre sigillée gallo-romaine. Lieux de production du Haut Empire: implantations, produits, relations, Documents d'archéologie française. París.

Martín-Garnier 1977: Martin, Th. y Garnier, J. F., "Céramique arétine et sigillée sudgaloise prècoce d'Excisum à Villeneuve-sur-Lot (Lot-etGaronne)», Figlina, 2. Lyon.

NiEto 1986: NiETO, J., «El precio Culip IV: Observaciones sobre la organización de los talleres de Terra Sigillata de La Graufesenque», Archaeonautica, 6. París.

- et alii 1989: Excavacions arqueològique subaquàtiques a Cala Culip, I. Gerona.

Oswald 1964: Oswald, F., Index of Potters'Stamps on Terra Sigillata (Samian Ware). London.

Oswald-Pryce 1966: Oswald, F. y Pryce, D., An Introduction to the study of Terra Sigillata. London, (1. ${ }^{a}$ ed. en 1920).

Pérez Almoguera et alii 1988: Pérez Almoguera, A., Amare, T., GarCÉS, I. y MARCO, T., Els materials del jaciment romá de Raïmat. Lleida. 
Pérez González 1989: Pérez González, C. : Cerámica romana de Herrera de Pisuerga (Palencia, España). La Terra sigillata. Universidad Internacional SEK. Santiago de Chile.

PICÓN et alii 1972-73: PICÓN et alii, "Recherches sur le céramiques d'Ateivs trouvées en Gaule", RCRF Acta, XIV-XV.

Puccl 1977: Puccl, G., "Le terre sigillate italiche, galliche e orientali», L'Instrumentum domesticum di Ercolano e Pompei nella prima età imperiale. Quaderni di cultura materiale, I. Roma.

- 1985: "Terra sigillata itálica", Atlante delle Forme Ceramiche II, Enciclopedia dell'Arte Antica Classica e Orientale. Roma.

Romero 1985: Romero Carnicero, M. V., Numancia I. La terra sigillata. EAE, 146. Madrid.

Sanchez-Lafuente 1985: Sánchez-Lafuente Pérez, J., Comercio de cerámicas romanas en Valeria. Cuenca.

- 1990: Terra sigillata de Segóbriga y ciudades del entorno: Valeria, Complutum y Ercávica. Madrid.

SCHNURBEIN 1982: SchNuRBEIN, S., Die unverzierte terra sigillata aus Ha/tern, Bodenaltertümer Westfalens, 19. Münster.

SIMPSON 1976: SIMPSON, G., «Decorated Terra Sigillata at Montans (Tarn) form the Manuscript of Elie Rossignol at Montans", Britannia, VII.

STENICO 1968: STENiCO 1968, «Fabbricanti di vasi Aretini», Estratto dalla Enciclopedia dell'Arte Antica Classica e Orientale. Roma.

TAPONECO 1974: "La fábrica pisana di Ateio", Antichitá Pisane, 2. Pisa.

Thuaul-Vernhet 1986: Thuault, M. y Vernhet, A. «Le Rozier", La terre sigillée gallo-romaine. Lieux de production du Haut Empire: implantations, produits, relations. París.

VAnderhoeven 1984: Vanderhoeven, M., La terre sigillée, Cahiers de L'Institut Archeologique Liegeois, I. Liège.

VERNHET 1976: “Création flavienne de six services de vaisselle à la Graufesenque», Figlina, 1, págs. 13-27.

- 1986: "Centre de production de Millau. Atelier de La Graufesenque", La terre sigilée gallo-romaine. Lieux de production du Haut Empire: implantations, produits, relations. París.

WELLS 1977: WELLS, C. M. «Limplantation des ateliers de céramique sigillée en Gaule. Problématique de la recherche», Figlina, 2. Lyon.

Zarzalejos-Garcia 1987: Zarzalejos Paieto, M. M. Y Garcia Diaz, P., “Dos gemas talladas de La Bienvenida (Almodóvar del Campo, Ciudad Real"), Oretum, III. Ciudad Real.

Zarzalejos-Seldas 1987: Zarzalejos Prieto, M. M. y Seldas FernánDEZ, I., "Ánforas romanas en la Provincia de Ciudad Real», Oretum, III. Ciudad Real. 